\title{
EDUCAÇÃO MUSICAL A DISTÂNCIA: DESAFIOS E ALTERNATIVAS PROPOSTAS POR DUAS UNIVERSIDADES FEDERAIS BRASILEIRAS
}

\author{
Patrícia L. L. Mertzig Gonçalves de Oliveira, Tais Luciana Souza da Silva, Luciana Carolina Fernandes \\ de Faria
}

Universidade do Oeste Paulista - UNOESTE, Curso de Licenciatura em Música - FACLEPP, Presidente Prudente, SP. Email: patriciamertzig@gmail.com

\section{RESUMO}

Este artigo tem como objetivo identificar e analisar alguns desafios enfrentados pelo ensino de música a distância e as alternativas propostas por duas universidades federais brasileiras para resolver tais desafios. Buscamos alcançar tal objetivo por meio de coleta de informações na página virtual das universidades, em seus projetos pedagógicos, artigos, vídeos e entrevistas publicadas na página virtual do youtube. Identificamos que as universidades UFRGS e UFSCar preveem algumas das dificuldades do ensino a distância, como falta de familiaridade dos alunos com as TIC utilizadas, comprometendo a eficiência do processo de aprendizagem, e a dificuldade do aprendizado do instrumento musical. Tais universidades apresentam alternativas para amenizar essas dificuldades criando recursos para auxiliar o desenvolvimento dos estudantes, como, por exemplo, a utilização de um e-book como material didático.

PALAVRAS-CHAVE: Educação Musical; Educação a Distância; Licenciatura em Música; UFRGS e UFSCar.

\section{DISTANCE MUSIC EDUCATION: CHALLENGES AND ALTERNATIVES PROPOSALS BY TWO BRAZILIAN UNIVERSITIES}

\begin{abstract}
This article aims to identify and analyze some challenges faced by teaching music at distance and the alternatives proposed by two Brazilian federal universities to solve these challenges. We seek to achieve this by gathering information on the virtual page of these universities through projects of teaching, articles, videos and interviews published in the virtual page of youtube. We found that the UFRGS universities and UFSCar predict some of the difficulties of distance learning, such as lack of familiarity of students with ICT use, compromising the efficiency of the learning process, and the difficulty of learning a musical instrument. Such universities present alternatives to solve these difficulties by creating resources to assist the development of the students, for example, the use of an e-book as teaching material.
\end{abstract}

KEYWORDS: Musical Education; Distance education; Degree in music; UFRGS and UFSCar. 


\section{INTRODUÇÃO}

A Lei de Diretrizes e Bases no 9.394 de 1996 (BRASIL, 1996) trouxe novas perspectivas para a educação no país, e uma de suas alterações foi substituir a disciplina, então chamada de Educação Artística, por Arte. Nos documentos oficiais como os Parâmetros Curriculares Nacionais - PCN (BRASIL, 1997) apontam os conteúdos que poderiam ser desenvolvidos nessa disciplina, que seriam Artes Visuais, Dança, Teatro e Música. Porém, foi a Lei 11.769/2008 (BRASIL, 2008) que tratou especificamente do conteúdo musical e de sua obrigatoriedade no ensino regular, determinando inclusive o prazo de três anos para adequações por parte das instituições de ensino.

Esses dois momentos importantes para a educação musical no país geraram uma demanda por profissionais habilitados, assim, podemos observar um crescimento na oferta e na procura por curso superior de Licenciatura em Música. Visando atender essa demanda e indo ao encontro do crescente desenvolvimento da Educação a Distância no país, surgiram também cursos de licenciatura em música na modalidade a distância. Dois exemplos desses cursos são os oferecidos pela Universidade Federal do Rio Grande do Sul - UFRGS e pela Universidade Federal de São Carlos - UFSCAR, objetos de pesquisa investigados e relatados neste artigo.

Quando falamos de um curso de música EaD existem algumas particularidades que precisam ser observadas e cuidadosamente trabalhadas para que não hajam prejuízos nos processos de ensino e aprendizado dos conteúdos propostos.

Com o avanço das Tecnologias de Informação e Comunicação - TIC, em especial a internet, abriram novas possibilidades para a educação a distância, ao ponto de hoje se tornar difícil imaginar um curso a distância que não faça uso dos ambientes virtuais. A internet proporcionou experiências novas e interessantes para o processo de educação que os outros meios de educação a distância ainda não proporcionavam, como a possibilidade de interação entre professor e aluno, interação entre alunos em polos e cidades diferentes, por meio das redes sociais, chats, videoconferências, o acesso rápido e com baixo custo à materiais didáticos, além da experiência de uma leitura por hipertexto, possível por meio desta TIC.

A primeira lei que regulamenta a EaD foi também a LDB no 9394/1996 (BRASIL, 1996), que trouxe alteração para o ensino de Arte. Segundo Oliveira (2014, p. 27), com essa Lei a educação a distância "deixa de ter o caráter emergencial e supletivo, adquirindo reconhecimento em uma série de documentos, os quais definem os critérios e normas para a criação de cursos e programas ofertados em uma modalidade distinta do ensino presencial". A partir desse momento, ainda segundo Oliveira (2014), as instituições de ensino públicas e privadas se mobilizaram para oferecer cursos nessa modalidade. 
Como podemos perceber, existe uma grande abertura por parte do governo para a expansão e popularização da educação a distância, especialmente para a formação de docentes como aponta Mota (2010, p. 300)

Dessa forma, a modalidade EaD pode contribuir significativamente com o atendimento de demandas educacionais urgentes, dentre as quais, destacamse a necessidade de formação ou capacitação de mais de um milhão de docentes para a educação básica, bem como a formação continuada, em serviço, de um grande contingente de servidores das empresas públicas.

Destarte, neste contexto, o objetivo deste artigo é analisar os desafios enfrentados na implantação e desenvolvimento de alguns cursos de Licenciatura em Música na modalidade a distância, bem como alternativas propostas para superar tais desafios. Os cursos escolhidos como objeto de pesquisa foram os cursos de Licenciatura em Música oferecidos pela Universidade Federal do Rio Grande do Sul e pela Universidade Federal de São Carlos.

\section{METODOLOGIA}

Afim de coletar informações sobre os cursos das universidades supracitadas, foi feita uma pesquisa nas páginas virtuais das universidades, onde é possível observar o plano político pedagógicos dos cursos, vídeos institucionais e entrevistas publicadas na página virtual do youtube.

\section{RESULTADOS}

O artigo 80 da LDB de 1996 diz que "O Poder Público incentivará o desenvolvimento e a veiculação de programas de ensino a distância, em todos os níveis e modalidades de ensino, e de educação continuada" (BRASIL, 1996), e no parágrafo primeiro do referido artigo consta que "A educação a distância, organizada com abertura e regime especiais, será oferecida por instituições especificamente credenciadas pela União" (BRASIL, 1996). Neste contexto está inserido o curso de Licenciatura em Música da Universidade Federal do Rio Grande do Sul - UFRGS, que nasceu dentro do Programa Pró - Licenciatura Fase II do Governo Federal

Art. 2ㅇ O Pró-Licenciatura visa à melhoria da qualidade de ensino da Educação Básica, por meio da oferta de cursos de licenciatura, na modalidade de educação a distância, para formação inicial de professores em exercício na rede pública nos anos/séries finais do Ensino Fundamental e/ou Ensino Médio, nos sistemas estaduais e municipais de educação, sem licenciatura na disciplina em que estejam exercendo a docência (BRASIL, 2006). 
O curso da UFRGS foi oferecido inicialmente em 14 pólos, distribuídos por 5 estados brasileiros e em parceria com outras 6 Instituições de Ensino Superior. Para ingressar no curso, além de prestar vestibular com prova objetiva geral e prova especifica em música, o aluno precisa cumprir e se enquadrar nas exigências do Programa Pró - Licenciatura, uma delas determina que ele deve estar lecionando há pelo menos um ano na disciplina que deseja cursar.

Já na Universidade Federal de São Carlos - UFSCar, o curso oferecido recebe o nome de Licenciatura em Educação Musical, ele faz parte do Sistema UAB - Universidade Aberta do Brasil que, de acordo com Mota (2010, p. 300)

O Sistema UAB foi oficializado pelo decreto № 5.800, de 8 de julho de 2006, destacando a articulação e integração de instituições de ensino superior, municípios e estados, visando à democratização, expansão e interiorização da oferta de ensino superior público e gratuito no país, (...), preferencialmente para a área de formação inicial e continuada de professores da educação básica.

Como para o ingresso nas duas instituições o aluno precisa prestar prova de conhecimentos gerais e outra de conhecimentos específicos em música, ou seja, o aluno ingressante precisa ter certo conhecimento musical prévio. Apesar de ser um curso a distância, o aluno precisa estar ciente dos encontros presenciais que acontecem uma vez por semana nos polos e no caso do curso da UFSCar além do encontro semanal, estão previstos outros encontros que ocorreram um final de semana por semestre. Todas essas informações constam na página do curso de Licenciatura em Educação Musical da UFSCar ${ }^{1}$.

A não familiaridade com computador e internet, e a dificuldade de acesso a esses recursos podem ser um dos fatores que inibem alunos em potencial para realização de curso superior à distância. Embora as duas Intuições prevejam a oferta de Laboratório de Informática nos pólos de apoio presencial, estes nem sempre são em quantidade suficiente para atender todos os alunos. As atividades do curso acontecem por meio de ambiente de aprendizado virtual, e é possível encontrar também vários vídeos publicados no youtube de trabalhos realizados pelos alunos. Assim podemos perceber o quanto é essencial para o bom desenvolvimento do aluno nos cursos a distância o domínio e o fácil acesso a computador.

Para as Universidades cabe a responsabilidade de equipar os polos de apoio presencial com computadores e acesso a internet, e auxiliar o aluno ingressante em suas dificuldades de

${ }^{1}$ Cf. em http://betara.ufscar.br:8080/uab/em/menu-esquerdo/vestibular (acesso em 01/08/2015) 
adaptação com o ambiente virtual. Embora esta seja uma dificuldade vencida ao longo curso, ela pode, a princípio, gerar atraso no desenvolvimento e aprendizado, e ser um fator para evasão.

Outro desafio a ser vencido na implantação de curso a distância é a realidade social e a infraestrutura encontrada em cada pólo de apoio presencial. Dificuldade, esta, testemunhada no vídeo institucional de apresentação do Curso de Licenciatura em Música EaD da UFRGS, publicado no Youtube ${ }^{2}$. Nele dentre outros temas abordados por profissionais responsáveis pela implantação do curso e egressos, o técnico de informática, profissional essencial para implantação de cursos a distância, relata que a falta de recursos tecnológicos de alguns pólos, sobretudo a dificuldade de optar por tecnologias e implantá-las em lugares onde não há nem telefonia móvel.

Sobre tais dificuldades de acesso e adaptação, identificamos na grade curricular dos cursos, algumas disciplinas como Instrumentalização para EaD e Acesso a Informação na UFRGS e Letramento Digital, Introdução a Educação a Distância, Educação a Distância para Educação Musical, Letramento Digital, Introdução aos recursos tecnológicos musicais e tecnologia para internet na UFSCar, que tem como objetivo dar suporte e capacitar o aluno à servir-se adequadamente dos recursos disponíveis no ambiente virtual e participar das atividades propostas de forma efetiva.

Acessando a página virtual da UFSCar, é possível ter acesso ao Projeto Pedagógico do curso (UFSCAR, 2010). Nele constam algumas informações sobre medidas adotadas pelo curso para promover uma melhor formação aos seus alunos. Uma destas medidas é a preocupação no preparo do material didático, em ser oferecido em meios diferentes a fim de oferecer ao aluno mais um tipo de experiência e contato com os conteúdos abordados nas disciplinas.

Para tanto, serão produzidos materiais para cada disciplina utilizando, no mínimo, 3 diferentes tipos de mídia, incluindo o ambiente virtual de aprendizagem, vídeos explicativos e outros recursos apropriados ao objetivo específico (a ênfase em materiais de áudio e vídeo ou impressos irá depender da natureza do assunto estudado) (UFSCAR, 2010, p. 47).

O Projeto Pedagógico (UFSCAR, 2010) aponta, também para a importância de diversos laboratórios virtuais, com a preocupação em oferecer experiências práticas aos alunos.

Serão criados laboratórios virtuais de: educação musical; edição de partituras; produção de EAD; multimídia; e Criação musical 1-2. De modo que se propicie melhor aprendizagem e facilitem a prática inclusive para se otimizar algumas das atividades presenciais. (UFSCAR, 2010, p. 48)

\footnotetext{
${ }^{2}$ Cf. em https://www.youtube.com/watch?v=NeZJYii4Kc4
} 
Além das informações sobre o curso, grade curricular, professores, plano político pedagógico, identificamos também que a universidade desenvolve o oferece jogos musicais para auxiliar o desenvolvimento dos estudantes. Para acessar tais aplicativos, basta que o aluno acesse a página virtual ${ }^{3}$ disponibilizado pela instituição, realize o download e instale o plugin do Unity 3D, grande aplicativo motor de desenvolvimento de games.

Na página virtual de perguntas frequentes ${ }^{4}$ sobre o curso, a universidade esclarece que não é necessário que o estudante tenha computador com acesso à internet banda larga em casa, contudo alerta que, caso não tenha, é conveniente que o aluno realize as atividades on-line no polo de apoio presencial. Assim, destaca-se certa dificuldade que o aluno pode encontrar no acesso, levando-nos a questionar se referido curso é mesmo possível à todos. Esta instituição de ensino busca, então, amenizar tal dificuldade oferecendo boa estrutura e suporte aos estudantes que mais precisarem.

Analisando ainda artigos que discutem as questões do curso de Educação Musical a distância oferecido pela UFRGS, identificamos a proposta de livros eletrônicos (e-book) criados como um método de teclado e violão à distância para utilização das novas TIC.

$\mathrm{Na}$ interdisciplina chamada Seminário Integrador, encontram-se quinze Unidades de Estudo por semestre, que remetem aos E-books Teclado Acompanhamento e Violão Acompanhamento. Cada um dos E-books possui site próprio, contendo o material digital educacional do curso (ROSAS, WESTERMANN, 2009, p. 4). Grifo do autor.

Os autores também apresentam a descrição de tais e-books, que apresentam um enfoque no uso do instrumento como apoio harmônico, para aplicação como acompanhamento.

A principal característica de ambos é o fato de estarem mais focados na formação do musico capaz de cantar e de se acompanhar ao instrumento com destreza, do que na do performer em sentido mais convencional. Não se tem como objetivo formar um instrumentista virtuoso, com amplo domínio técnico nem dedicado ao repertório tradicional erudito. A busca principal está no desenvolvimento de habilidades que sejam úteis para professores de música do ensino regular da Escola Básica (ROSAS, WESTERMANN,2009, p. 6).

Assim, destacamos dois grandes desafios enfrentados pelos cursos de Educação Musical a Distância: o acesso e a familiaridade com os ambientes virtuais que servem de suporte para os cursos analisados, e o ensino técnico e prático do instrumento musical. Identificamos também como os cursos supracitados buscam superar tais desafios.

\footnotetext{
${ }^{3} \mathrm{Cf}$. em http://educacaomusical.sead.ufscar.br/jogos/

${ }^{4} \mathrm{Cf}$. em http://betara.ufscar.br:8080/uab/em/menu-esquerdo/perguntas-frequentes-1
} 


\section{DISCUSSÃO}

Embora exista nas duas instituições citadas neste trabalho, a preocupação em oferecer recursos para que o aluno tenha uma formação de qualidade, a falta de familiaridade por parte dos alunos, e também professores, com os ambientes e recursos virtuais (chats, ambientes virtuais de aprendizado, livros eletrônicos, entre outros) pode contribuir para o atraso do desenvolvimento da educação a distância no país. Esta característica nos leva a refletir se o acesso ao computador com internet é realmente disponível a todos, já que vivemos em um país onde há uma grande disparidade social.

Outro aspecto importante para nossa reflexão é o fato de que a $\mathrm{EaD}$ exige do aluno uma maior autonomia e disciplina de estudo, pois, embora um curso nesta modalidade de ensino não solicite a presença física do aluno diariamente na sala de aula, o contato por meio dos ambientes virtuais são tão necessárias e exigentes quanto no ensino presencial.

Além disso, o maior desafio dos cursos superiores de licenciatura em música a distância está relacionado ao ensino de instrumentos, pois conforme afirma Gohn (2010, p. 286) “o encontro presencial com um professor ainda é a forma mais comum para o aprendizado da técnica instrumental". Esta é uma das maiores questões, que ainda precisa ser mais discutida cientificamente e está longe de se esgotar, nesta área da educação musical a distância, já que uma postura errada ao tocar o instrumento pode causar até mesmo lesões físicas, além de influenciar na sonoridade.

Podemos observar um grande empenho por partes destas instituições no sentido de criar meios para que a prática instrumental seja realizada de maneira mais eficiente possível. Para isto há a criação dos livros eletrônicos, produção de materiais didáticos e oferta de salas de instrumentos nos pólos de apoio presencial. A UFSCar possui uma plataforma virtual denominada Livre Saber ${ }^{5}$ onde disponibiliza os materiais didáticos criados para educação a distância.

O ensino de instrumento a distância ser uma realidade em desenvolvimento e ser uma prática musical amplamente propagada na história da música e nos modelos de educação musicais mais tradicionais. Contudo, por que se limitar a uma prática de instrumento convencional, uma vez que esta prática a distância é, de certa forma, dificultada? Esta modalidade de ensino, muito mais que o ensino presencial, tem uma relação íntima com estética de música contemporânea, uma vez quem esta estética surgiu historicamente a partir da possibilidade que estes recursos sonoros e digitais proporcionavam. Assim, é possível utilizar de outros meios para ensinar música

\footnotetext{
${ }^{5}$ Cf.: http://livresaber.sead.ufscar.br:8080/ispui/
} 
ao aluno da graduação, como a composição por meio do computador, a edição de áudio, a exploração da estética desta música contemporânea.

Tais abordagens que poderiam expandir as práticas musicais nos ambientes escolares, indo além da música tonal e do canto coletivo e expandindo, também, a experiência musical dos alunos e a garantia de um resultado artístico musical mais interessante por não depender de uma técnica instrumental que é tão específica e de difícil domínio. Desta forma, destacamos que o objetivo maior da educação musical na escola não é tornar os alunos instrumentistas, mas sim conhecedores e críticos desta expressão artística.

\section{CONCLUSÃO}

A educação superior a distância é um assunto novo e em grande expansão, em especial no contexto da educação musical. O fato da EaD estar se tornando uma importante ferramenta para a educação superior no país é indiscutível, porém, no que se refere a educação musical, é necessário ainda que alguns conceitos, prioridades e metodologias sejam discutidos, a fim de os cursos a distância não se tornem apenas uma adaptação dos cursos presenciais, mas que, acima de tudo, possam servir-se de todas as experiências e dinâmica de estudo que só as novas TIC podem proporcionar ao estudante.

\section{REFERÊNCIAS}

BRASIL. Lei de Diretrizes e Bases da Educação Nacional. Lei9.394 de 20 de Dezembro de 1996. Estabelece as diretrizes e bases da educação nacional. Brasília: Presidência da República, 1996.

- Ministério da Educação e do Desporto. Secretaria da Educação Fundamental. Parâmetros Curriculares Nacionais: Arte. Brasília. 1997.

. Ministério da Educação. Fundo Nacional de Desenvolvimento da educação. Resolução $\mathbf{n}^{\circ}$ 49, de 29 de dezembro de 2006. Estabelece orientações e diretrizes para a concessão de bolsas de estudo e de pesquisa para participantes do Pró-Licenciatura, no âmbito do MINISTÉRIO DA EDUCAÇÃO.

. Lei 11.769, de 18 de Agosto de 2008. Altera a Lei $\mathrm{n}$ ㅇ 9.394, de 20 de dezembro de 1996, Lei de Diretrizes e Bases da Educação, para dispor sobre a obrigatoriedade do ensino da música na educação básica. Brasília: Presidência da República, 2008.

GOHN, Daniel M. EAD e o estudo da música. In Formiga, Manuel Marcos Maciel, Fredric M (Fredric Michale), 1939. Educação a Distância: o estado da arte. São Paulo: Pearson Prentice Hall, 2010. 
MOTA, Ronaldo. A Universidade Aberta do Brasil. In Formiga, Manuel Marcos Maciel Litto, Fredric M. (Fredric Michael), 1939. Educação a Distância: o estado da arte. São Paulo: Pearson Prentice Hall,2010.

OLIVEIRA, Silvana Aparecida Guietti de. A FORMAÇÃO DE PROFESSORES NO ENSINO SUPERIOR A DISTÂNCIA: LIMITES E POSSIBILIDADES DE INSERÇÃO E ASCENSÃO PROFISSIONAL. $159 \mathrm{f}$. Dissertação (Mestrado em Educação) - Universidade Estadual de Maringá. Orientadora: Maria Luisa Furlan Costa. Maringá, 2014.

ROSAS, Fátima W.; WESTERMANN, Bruno. Método de Teclado e Violão à Distância com a utilização das novas TICs. In: Revista RENOTE - Novas Tecnologias na Educação. V. 7 № 2, outubro, 2009. ISSN 1679-1916.

UFSCAR. Projeto Pedagógico. Curso de Licenciatura em Educação Musical. Para turmas ingressantes a partir de 2010. Modalidade Educação a Distância. Disponível em http://betara.ufscar.br:8080/uab/em/projeto-pedagogico-2010. 